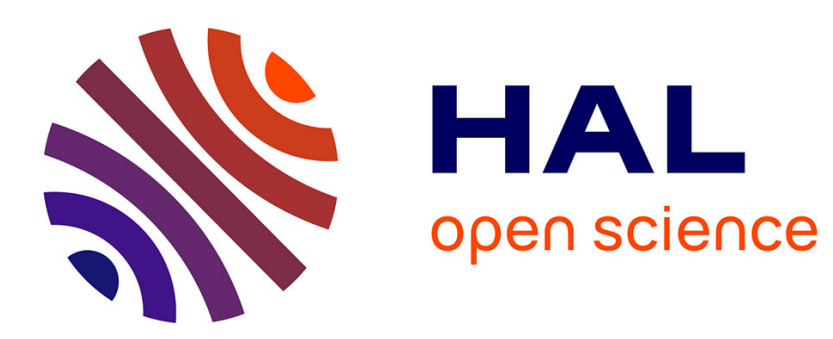

\title{
Radial trends in black spruce wood density can show an age-and growth-related decline
}

Wei Xiang, Mathew Leitch, David Auty, Emmanuel Duchateau, Alexis Achim

\section{To cite this version:}

Wei Xiang, Mathew Leitch, David Auty, Emmanuel Duchateau, Alexis Achim. Radial trends in black spruce wood density can show an age-and growth-related decline. Annals of Forest Science, 2014, 71 (5), pp.603-615. 10.1007/s13595-014-0363-7 . hal-01102584

\section{HAL Id: hal-01102584 \\ https://hal.science/hal-01102584}

Submitted on 13 Jan 2015

HAL is a multi-disciplinary open access archive for the deposit and dissemination of scientific research documents, whether they are published or not. The documents may come from teaching and research institutions in France or abroad, or from public or private research centers.
L'archive ouverte pluridisciplinaire HAL, est destinée au dépôt et à la diffusion de documents scientifiques de niveau recherche, publiés ou non, émanant des établissements d'enseignement et de recherche français ou étrangers, des laboratoires publics ou privés. 


\title{
Radial trends in black spruce wood density can show an age- and growth-related decline
}

\author{
Wei Xiang • Mathew Leitch • David Auty • \\ Emmanuel Duchateau • Alexis Achim
}

Received: 24 July 2013 / Accepted: 26 January 2014 /Published online: 14 February 2014

(C) INRA and Springer-Verlag France 2014

\begin{abstract}
- Context Wood density variation affects structural timber performance and is correlated with several potentially confounding factors, such as cambial age, position in the stem and growth rate. To date, these relationships have not been comprehensively quantified in black spruce (Picea mariana (Mill.) B.S.P.).

- Aims The aim of this study was to describe the variation in annual ring density in black spruce as a function of cambial age, stem height and growth rate.

- Methods Radial density profiles from 107 black spruce trees were analysed using a two-stage modelling approach. First, the parameters of a nonlinear function were estimated
\end{abstract}

Handling Editor: Jean-Michel Leban

Contribution of the co-authors Wei Xiang was the principal investigator for this study. He undertook sample processing and laboratory measurements, carried out the main data analyses and wrote the manuscript. Mathew Leitch was the main supervisor for the project. He supervised the work and helped in developing the methodology for the study, interpreting results and revising earlier drafts until final approval.

David Auty contributed to the development of the model and to the interpretation and presentation of the statistical results and revised the text.

Emmanuel Duchateau assisted the first author in developing the modelling approach and in finding a strategy to increase the convergence of the nonlinear models. He also contributed to the interpretation and presentation of the statistical results.

Alexis Achim was the co-supervisor for the project. He assisted with developing the methodology for the study, supervised the development of the model and revised the text.

W. Xiang $(\bowtie) \cdot$ M. Leitch

Faculty of Natural Resources Management, Lakehead University,

Thunder Bay, ON, Canada P7B 5E1

e-mail: wxiang@lakeheadu.ca

D. Auty $\cdot$ E. Duchateau $\cdot$ A. Achim

Département des sciences du bois et de la forêt, Université Laval, Sainte-Foy, Québec, Canada G1V 0A6 separately for individual samples. Linear regression was then used to model the parameters obtained in the first stage as functions of internal and external tree descriptors.

- Results Annual ring density was high near the pith and declined rapidly in the first 15 annual rings before increasing to more stable values between rings 25 and 60 . However, just below $25 \%$ of the samples showed a gradual decline towards the bark, typically after ring 60 .

- Conclusion Describing and quantifying radial density patterns, including the decline close to the bark, will help further our understanding of the links between tree growth and ring density over the life of the tree.

Keywords Wood density · Black spruce · Two-stage model . X-ray densitometry

\section{Introduction}

Black spruce (Picea mariana (Mill.) B.S.P.) is one of the most important and valuable species for both lumber and pulpwood production in Eastern and Central Canada and an important commercial and reforestation species from the Atlantic Coast to Manitoba (Boyle et al. 1989; Zhang 1998). In the boreal forest of Canada, black spruce is harvested predominantly from natural stands. Consequently, an understanding of the influence of natural forest dynamics on black spruce wood attributes is important in order to formulate appropriate management strategies for maximizing the value of the resource at harvest.

As demand for wood and wood products has increased in recent decades, research efforts have focused more intensively on wood and fibre quality attributes in addition to volume production (Jozsa and Middleton 1994; Evans 1994; Koubaa et al. 2000; Franceschini et al. 2012). Of these attributes, wood density is one of the most important and useful wood quality 
indicators (Panshin and de Zeeuw 1980; Zhang et al. 1996) and is closely correlated with the mechanical properties of wood (Zhang et al. 1993; Koga and Zhang 2004) and with certain strength properties of paper (van Buijtenen 1982). Furthermore, with growing interest in forest carbon sequestration, wood density can also be used in allometric equations as an essential component of aboveground biomass estimations (Ketterings et al. 2001; De Vries et al. 2006).

Previous studies have quantified the effects of the different sources of variation, i.e. internal variables such as cambial age, ring width and genetic origin (Alteyrac et al. 2005; Jyske et al. 2008; Savva et al. 2010) and external variables such as position along the stem, site quality and climate (Wang et al. 2002; Bouriaud et al. 2004; Guilley et al. 2004), on annual ring density. Within-stem variations in ring density may consequently be related to various intrinsic and extrinsic sources, which have potentially confounding effects. In this context, a modelling approach based on the observed effects of important variables, such as cambial age, annual growth rate and position along the stem, on annual ring density can help further our understanding of these complex interrelationships.

In spruces, the radial pattern of variation in wood density typically shows a rapid decrease near the pith followed by a more gradual increase towards the bark (Panshin and de Zeeuw 1980), a trend that has been confirmed specifically for black spruce (Zhang et al. 2002; Alteyrac et al. 2005). Despite having been investigated extensively, the reported correlation between growth rate and wood density is not consistent among studies. For example, a negative correlation between annual ring width and wood density has been reported in both Norway spruce (Picea abies (L.) Karst.) and Sitka spruce (Picea sitchensis (Bong.) Carr.; Franceschini et al. 2010, 2013; Gardiner et al. 2011). Also in Sitka spruce, Simpson and Denne (1997) reported that the strength of this negative correlation increased from the stem base to the tree tip, for a given cambial age. Conversely, in balsam fir (Abies balsamea), Koga and Zhang (2004) found a significant negative correlation between growth rate and density below $3 \mathrm{~m}$ in the stem, but there was no significant effect above this height. Wimmer and Downes (2003), on the other hand, reported a positive relationship between ring width and ring density in Norway spruce, which was associated with higher late-season rainfall. However, a negative relationship was found when faster radial growth was a result of high earlyseason rainfall. Besides changes linked to climatic conditions, the relationship between ring width and wood density may also be altered by the application of fertilization (Mäkinen et al. 2002) and thinning treatments (Jaakkola et al. 2005).

In black spruce, some studies have reported that ring width is not significantly correlated with wood density in mature wood (Risi and Zeller 1960; Hall 1984). Conversely, negative correlations between wood density and growth-related traits (diameter at breast height (DBH), tree height and bole volume) were detected by Zhang and Morgenstern (1995). Zhang et al. (1996) also reported moderate negative correlations between wood density and growth rate in 15-year-old black spruce trees, but these could be reversed for given provenances, environmental conditions and geographical locations. More recently, Koubaa et al. (2000) observed the combined effects of cambial age and growth rate and concluded that the negative correlation between ring width and wood density in black spruce was not significant beyond a cambial age of 25 years.

The effect of height along the stem on the radial patterns of variation in wood density has received rather less attention. In Norway spruce, Mäkinen et al. (2007) found no significant effect of height on ring density, whilst Jyske et al. (2008) found a small positive height effect (3-6\%) for a given cambial age. In black spruce, Alteyrac et al. (2005) reported a large variation in density among stem heights, but the variation was smaller in mature wood than juvenile wood.

The aim of this study was to investigate the relationships between cambial age, growth rate and height along the stem with annual wood density variation in black spruce trees. More specifically, we present the development of a model which describes the general within-stem patterns of variation in average ring density in black spruce from naturally regenerated, unmanaged stands. The resulting model was used to produce simulations of annual ring density variation in black spruce trees of different ages and growth rates.

\section{Materials and method}

\subsection{Sampling}

Trees were sampled in an area $400 \mathrm{~km}$ northwest of Thunder Bay, Ontario, Canada. A total of 13 stands were sampled from natural forests located in the Lake St. Joseph Ecoregion, between $51^{\circ} 42^{\prime} \mathrm{N}$ and $52^{\circ} 6^{\prime} \mathrm{N}$ and between $90^{\circ} 3^{\prime} \mathrm{W}$ and $94^{\circ} 31^{\prime} \mathrm{W}$, at an elevation of $400 \mathrm{~m}$ (Table 1). Mean annual temperature varied between -1.7 and $1.0{ }^{\circ} \mathrm{C}$, mean annual precipitation ranged between 613 and $787 \mathrm{~mm}$, mean summer rainfall between 244 and $299 \mathrm{~mm}$, and the mean length of the growing season between 162 and 179 days.

Each stand was pre-selected according to the following criteria: (1) species composition (dominated by black spruce), (2) stand age ( $>50$ years old) and (3) crown closure ( $>55 \%$ crown closure). Since they were unmanaged stands, no previous silvicultural treatments had been performed. Three temporary sample plots (TSP) with a plot radius of $5.64 \mathrm{~m}$ $\left(100 \mathrm{~m}^{2}\right)$ were established at each site.

Three trees were selected for destructive sampling from each TSP: (1) the tree with the largest DBH (measured $1.3 \mathrm{~m}$ aboveground level), (2) the tree with the median DBH and (3) the tree with the DBH closest to the average of the quadratic 
Table 1 Mean (SD) stand-, tree- and ring-level characteristics for each site

\begin{tabular}{lllllllllll}
\hline $\begin{array}{l}\text { Site } \\
\text { no. }\end{array}$ & $\begin{array}{l}\text { Latitude } \\
\text { (north) }\end{array}$ & $\begin{array}{l}\text { Longitude } \\
\text { (west) }\end{array}$ & $\begin{array}{l}\text { Elevation } \\
(\mathrm{m} . \mathrm{a} . \mathrm{s} .1)\end{array}$ & $\begin{array}{l}\mathrm{BA} \\
\left(\mathrm{m}^{2} \mathrm{ha}^{-1}\right)\end{array}$ & $\begin{array}{l}\text { Age } \\
(\mathrm{years})\end{array}$ & $\begin{array}{l}\mathrm{DBH} \\
(\mathrm{cm})\end{array}$ & $\begin{array}{l}\text { Height } \\
(\mathrm{m})\end{array}$ & $\begin{array}{l}\mathrm{H}_{100} \\
(\mathrm{~m})\end{array}$ & RW (mm) & Ring density (kg m $\left.{ }^{-3}\right)$ \\
\hline 1 & $51^{\circ} 29^{\prime}$ & $93^{\circ} 46^{\prime}$ & 410 & 37.13 & 107 & 16.1 & 16.4 & 19.5 & $0.8(0.51)$ & $509.28(67.26)$ \\
2 & $51^{\circ} 33^{\prime}$ & $93^{\circ} 52^{\prime}$ & 390 & 33.11 & 60 & 14.8 & 14.3 & 21.9 & $1.6(0.63)$ & $459.53(51.41)$ \\
3 & $51^{\circ} 30^{\prime}$ & $93^{\circ} 48^{\prime}$ & 430 & 30.05 & 100 & 14.0 & 14.4 & 16.0 & $0.9(0.42)$ & $525.22(51.67)$ \\
4 & $51^{\circ} 9^{\prime}$ & $91^{\circ} 24^{\prime}$ & 380 & 40.33 & 78 & 15.6 & 16.0 & 22.3 & $1.1(0.68)$ & $514.37(62.44)$ \\
5 & $51^{\circ} 8^{\prime}$ & $91^{\circ} 25^{\prime}$ & 380 & 45.33 & 83 & 13.6 & 14.7 & 18.0 & $0.9(0.38)$ & $507.25(56.02)$ \\
6 & $51^{\circ} 43^{\prime}$ & $91^{\circ} 43^{\prime}$ & 400 & 41.97 & 136 & 19.4 & 19.0 & 18.0 & $0.8(0.52)$ & $496.21(57.57)$ \\
7 & $51^{\circ} 42^{\prime}$ & $91^{\circ} 47^{\prime}$ & 400 & 41.22 & 127 & 19.5 & 18.4 & 19.8 & $0.8(0.43)$ & $501.35(69.84)$ \\
8 & $51^{\circ} 43^{\prime}$ & $91^{\circ} 46^{\prime}$ & 400 & 35.47 & 138 & 19.1 & 18.0 & 18.3 & $0.9(0.44)$ & $511.82(62.52)$ \\
9 & $51^{\circ} 41^{\prime}$ & $91^{\circ} 50^{\prime}$ & 400 & 40.23 & 78 & 14.1 & 14.6 & 19.5 & $1.0(0.46)$ & $477.63(57.38)$ \\
10 & $51^{\circ} 40^{\prime}$ & $91^{\circ} 52^{\prime}$ & 400 & 43.48 & 74 & 13.0 & 13.1 & 17.1 & $0.9(0.44)$ & $504.08(63.07)$ \\
11 & $51^{\circ} 41^{\prime}$ & $91^{\circ} 51^{\prime}$ & 400 & 39.26 & 125 & 19.7 & 20.2 & 19.8 & $0.9(0.36)$ & $493.30(66.80)$ \\
12 & $51^{\circ} 42^{\prime}$ & $91^{\circ} 44^{\prime}$ & 400 & 41.19 & 90 & 15.7 & 15.7 & 18.4 & $0.9(0.53)$ & $497.43(62.23)$ \\
13 & $51^{\circ} 42^{\prime}$ & $91^{\circ} 49^{\prime}$ & 400 & 33.51 & 80 & 22.1 & 19.1 & 23.2 & $1.5(0.66)$ & $489.89(56.84)$ \\
\hline
\end{tabular}

$H_{100}$ is the site index, calculated as the dominant height at 100 years (Plonski 1956)

m.a.s.l meters above sea level, $B A$ basal area of the living trees per hectare, $R W$ annual ring width

mean DBH and the DBH of the smallest tree of the plot, hereafter described as dominant, co-dominant and intermediate trees (Smith et al. 1997), respectively. This ensured that a large range of radial growth rates was represented in the dataset. Mean tree- and ring-level characteristics for each dominance level are shown in Table 2. After felling, the total height of each sample tree was recorded before 5-cm-thick transverse discs were cut at predetermined heights. In the dominant and co-dominant trees, discs were taken at $0.5,1.3$ and $1.75 \mathrm{~m}$, the live crown base (LCB, defined as the lowest live branch) and at two equidistant points between $1.75 \mathrm{~m}$ and LCB. Discs at successive heights from ground level were labelled M1, M2, M3, M4, M5 and M6, respectively. In the intermediate trees, only the M2 disc $(1.3 \mathrm{~m})$ was sampled as discs beyond this height were generally very small. Sampling positions were adjusted to avoid branch whorls or obvious stem damage, and discs $<8 \mathrm{~cm}$ in diameter were omitted from the study.

\subsection{Wood density measurements}

The discs were cut longitudinally through the pith and then into radial strips with a constant thickness of $2 \mathrm{~mm}$ in the longitudinal direction and a width of $25 \mathrm{~mm}$ tangentially. The samples were placed in a conditioning chamber set at $60 \%$ relative humidity and $20{ }^{\circ} \mathrm{C}$ until they reached a constant mass, corresponding to an equilibrium moisture content of approximately $12 \%$. The samples were then scanned with an X-ray beam at a resolution of $40 \mu \mathrm{m}$ in a QTRS-01X Tree Ring Analyzer (Quintek Measurement Systems Inc., Knoxville, TN, USA). No extractions were carried out prior to scanning because the extractives content of black spruce wood is known to be very low (Lohrasebi et al. 1999).

The X-ray densitometry values were calibrated using a gravimetrically determined target density for each specimen, calculated from the mass and volume of each sample. After scanning, the transition point between successive annual rings was determined as the point of equidistance between the maximum value of the previous ring and the minimum value of the current ring. Any incomplete or false rings and rings with compression wood or branch traces were excluded from the dataset. Only data where cambial age (CA) was less than or equal to 140 years were used for the development of the models because only one tree had a higher CA. Including damaged or small-diameter discs, samples from a total of ten trees were omitted from the analysis. The final dataset

Table 2 Mean (SD) tree- and ring-level characteristics for each dominance class

\begin{tabular}{lllllll}
\hline Dominance class & Age (years) & DBH $(\mathrm{cm})$ & Height $(\mathrm{m})$ & No. of rings & RW $(\mathrm{mm})$ & Ring density $\left(\mathrm{kg} \mathrm{m}^{-3}\right)$ \\
\hline Dominant & 96 & 20.2 & 18.3 & 17,466 & $1.13(0.59)$ & $486.03(59.21)$ \\
Co-dominant & 95 & 14.7 & 15.9 & 15,178 & $0.82(0.45)$ & $512.83(62.14)$ \\
Intermediate & 92 & 11.6 & 14.4 & 2,483 & $0.62(0.32)$ & $535.19(65.98)$ \\
\hline
\end{tabular}

$R W$ annual ring width 
therefore consisted of density data from 35,127 annual rings in 450 radial strips from 107 trees sampled at 13 sites.

Due to very slow radial growth in several samples, it proved impossible to delineate the limits of earlywood and latewood with consistent accuracy in the densitometry data. To examine the factors that influenced density in narrow rings, thin radial-transverse cuts were prepared for examination under a microscope. On each sample, the 20 rings closest to the bark were examined to determine ring width, earlywood width and latewood width. The limits between wood types were determined visually and width measurements were made using the Motic Images Plus 2.0 digital microscopy software (Marconetto 2010). Eight pairs of high- and low-density ring series were compared in this way. A series of conditions were applied to ensure that each pair was directly comparable, i.e. the two discs were from the same site, from trees of the same dominance class and age (maximum difference of 10 years), and from the same sampling height. The absence or presence of a density decline near the bark was used to determine whether discs represented either a high- or low-density ring series. The ring series were selected randomly from all those that met the specified conditions. One pair of representative ring series is shown in Fig. 1.

\subsection{Model development}

Due to the hierarchical structure of the data, with observations on annual rings nested within discs, themselves grouped in trees clustered within sites, nonlinear mixed-effects modelling techniques were first applied (Guilley et al. 2004; Franceschini et al. 2010; Gardiner et al. 2011). However, in our initial modelling efforts, we found that the variation among individual discs followed many distinctive pith-tobark patterns, which could not easily be described by a single equation. To circumvent this problem, a two-stage modelling strategy was used (Achim et al. 2006; McLane et al. 2011; Duchateau et al. 2013). First, the parameters of a nonlinear equation describing the pith-to-bark profiles of annual ring density were estimated for each disc separately. The parameter values obtained in the first stage were then modelled as functions of tree- and disc-level variables using linear regression.

\subsubsection{Stage 1: Fitting nonlinear model forms to individual discs}

Several nonlinear model forms used to model wood density in other species (Franceschini et al. 2010; Gardiner et al. 2011) were tested, but performed poorly due to a low rate of convergence among discs. This was attributed to a decline in wood density that was observed in the outerwood of a proportion of the samples that the models could not describe. Instead, we found that the radial pattern of ring density could be more appropriately described using a Michaelis-Menten equation with the addition of two exponential terms.

$\mathrm{RD}=b_{0} \cdot e^{-b_{1} \cdot \mathrm{CA}}+\frac{b_{2} \cdot \mathrm{CA}}{b_{3}+\mathrm{CA}}-e^{-b_{4} \cdot \mathrm{CA}}+\varepsilon$

where $\mathrm{RD}$ is the mean ring density of the ring (in kilograms per cubic metre), CA is cambial age (years), and $b_{0}, b_{1}, b_{2}, b_{3}$ and $b_{4}$ are empirically determined parameters. Parameter $b_{0}$ denotes the intercept when CA approaches a theoretical value of $0 ; b_{1}$ denotes the scale parameter of the early decrease in RD. The error term $\varepsilon$ was assumed to be normally distributed, with $N\left(0, \sigma^{2}\right)$. The first exponential term $b_{0} \cdot e^{-b_{1} \cdot \mathrm{CA}}$ has a value which decreases rapidly in the first few annual rings and then gradually approaches an asymptote close to zero. The second part of the equation is a Michaelis-Menten function where $b_{2}$ reflects the pseudo-asymptotic RD of mature wood and $b_{3}$ denotes the rate of progression between this asymptote and a minimum value reached in the juvenile period (Auty and Achim 2008; Auty et al. 2012). In the last part of the equation, the $b_{4}$ parameter allows for a decline in RD that can occur at high cambial ages, which can override the asymptotic value of $b_{2}$.

The optim function in the R statistical programming environment (R Core Team 2013) was used to search iteratively for the best combination of parameters in each disc, i.e. those

\section{Decline}

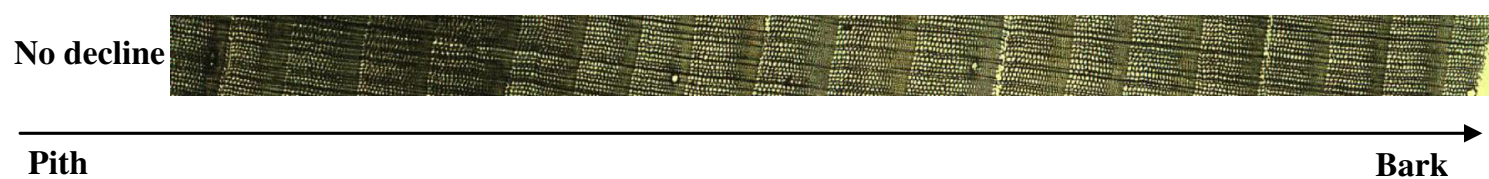

Fig. 1 Radial-tangential microscopy images $(\times 16)$ from a pair of ring series showing a decline and no decline, respectively, in wood density near the bark. The samples were taken from dominant trees from the same site (site 6) that were of a similar age (135 and 134 years old, respectively) and from adjacent sampling heights (M5 and M4, respectively) 
which minimized the sum of squared residuals. Based on a visual inspection of each radial profile, the specific conditions for the inclusion of the exponential term containing the $b_{4}$ parameter were: (1) when a declining trend in RD was observed close to the bark in the mature wood zone (i.e. $\mathrm{CA}>25$ ) and (2) when the decline continued for a period of at least 20 years. Convergence was achieved for $85 \%$ of the radial samples using the optim package. For the remaining samples, the starting values were entered manually, so that we were able to estimate parameters for the entire dataset. Model fit was assessed through a combination of visual analysis of plots of residuals against fitted values and explanatory variables, fit indices $\left(R^{2}\right)$ and selected model error statistics (Parresol 1999).

$\mathrm{ME}=\frac{\sum y_{i}-\widehat{y}_{i}}{n}$

$|\mathrm{ME}|=\frac{\sum\left|y_{i}-\widehat{y}_{i}\right|}{n}$

$\mathrm{RMSE}=\sqrt{\frac{\sum y_{i}-\widehat{y}_{i}}{n}}$

$\mathrm{ME} \%=\frac{100}{n} \sum \frac{y_{i}-\hat{y}_{i}}{\widehat{y}_{i}}$

$|\mathrm{ME}| \%=\frac{100}{n} \sum \frac{\left|y_{i}-\hat{y}_{i}\right|}{\widehat{y}_{i}}$

which represent the mean error, mean absolute error, root mean square error, mean percentage error and mean absolute percentage error, respectively. In these equations, $y_{i}$ is the observed value, $\widehat{y}_{i}$ the predicted value, and $n$ is the number of observations.

\subsubsection{Stage 2: Linear models for each parameter of the disc-level profiles}

Once the parameters of Eq. 1 had been estimated for each disc, linear mixed-effects models were fitted to each vector of parameter values in turn. The general form of the models can be expressed as

$Y_{i}=\boldsymbol{X}_{i} \boldsymbol{\beta}+\boldsymbol{Z}_{i} \boldsymbol{b}_{i}+\varepsilon_{i}$

where $Y_{i}$ represents parameters $b_{0}, b_{1}, b_{2}, b_{3}$ and $b_{4}$ in Eq. $1 ; X_{i}$ is the vector of fixed effects for the parameter of interest; $\beta$ the associated vector of fixed-effects parameters; $Z_{i}$ is a vector of random effects groups; $b_{i}$ is the vector of random effects variables; and $\varepsilon_{i}$ the residual error term. The random effects $b_{i}$ and within-group errors $\varepsilon_{i}$ are assumed to be independent for different groups and to be independent of each other for the same group and normally distributed; that is, $\varepsilon_{i}$ follows $N$ $\left(0, \sigma^{2}\right)$ and $b_{i}$ follows $N(0, \Psi)$ for each group, $\Psi$ being the variance-covariance matrix of random effects (Pinheiro and Bates 2000).

In order to find the most representative set of predictor variables and avoid potential issues with multicollinearity, the potential explanatory variables were divided into two categories.

1. Tree-level descriptors: tree age at breast height (Age, years); total height of the tree $(H)$; and mean ring width in the mature wood (i.e. from cambial age 25 to 60 ) at $1.3 \mathrm{~m}$ ( $\mathrm{RW}_{1.3}$, in millimetres)

2. Disc-level descriptors: disc position along the stem ( $h$, metres from stem base); average ring width of the first three rings near the pith $\left(\mathrm{RW}_{\mathrm{p}}\right.$, in millimetres); mean ring width in mature wood ( $\mathrm{RW}_{\mathrm{h}}$, in millimetres); and average growth rate (diameter or ring area) for different ranges of cambial age close to the bark ( $\mathrm{RW}_{\mathrm{b}}$, in millimeters, or $\mathrm{RA}_{\mathrm{b}}$, in square millimetres). In addition, we fitted a linear regression of annual ring width against cambial age for the rings close to the bark. The slope coefficient of the regression-described by Bigler and Bugmann (2003, 2004) as 'growth trend' (GT, in millimeters per year) was also screened as an input variable in the models since it is also closely related to tree vigour. Definitions of the abbreviations used for the explanatory variables in this study are given in Table 3 .

Considering the logical link between the selected variables and the behaviour of each parameter in Eq. 1, we hypothesised that $\mathrm{RW}_{\mathrm{p}}$ was likely to be included in the models for parameters $b_{0}$ and $b_{1}$. Similarly, we hypothesised that $\mathrm{RW}_{1.3}$ was related to parameter $b_{2}$. In addition, parameter $b_{4}$ was thought to be related to the age of the sample and the growth rate either close to the bark or in the mature wood zone. Thus, Age, $\mathrm{RW}_{\mathrm{b}}$ or $\mathrm{RA}_{\mathrm{b}}$, and $\mathrm{RW}_{\mathrm{h}}$ were candidate variables that described the competitive status of the tree at each height in the stem. Tree vigour-related variable GT was also considered. 
Table 3 Definitions of the abbreviations for the candidate explanatory variables used in this study

\begin{tabular}{ll} 
Abbreviations & Description (unit) \\
\hline Age & Tree age at breast height (years) \\
$H$ & Total height of the tree (m) \\
$h$ & Disc position along the stem from stem base (m) \\
$\mathrm{RW}_{\mathrm{p}}$ & Average ring width of the first 3 rings near the pith (mm) \\
$\mathrm{RW}_{\mathrm{h}}$ & $\begin{array}{l}\text { Mean ring width in mature wood (mm) } \\
\mathrm{RW}_{\mathrm{b}}\end{array}$ \\
$\begin{array}{l}\text { Average growth rate (diameter) for different ranges of } \\
\text { cambial age close to the bark (mm) }\end{array}$ \\
$\mathrm{RA}_{\mathrm{b}}$ & $\begin{array}{c}\text { Average growth rate (ring area) for different ranges of } \\
\text { cambial age close to the bark (mm }{ }^{2} \text { ) }\end{array}$ \\
$\mathrm{GT}$ & $\begin{array}{c}\text { Slope of the local regression of the annual ring width } \\
\text { against cambial age close to bark (mm year }\end{array}$ \\
$\mathrm{RW}_{1.3}$ ) & Mean ring width in the mature wood at $1.3 \mathrm{~m}(\mathrm{~mm})$
\end{tabular}

After we fitted the mixed-effects models for parameters $b_{0}$, $b_{1}, b_{2}$, and $b_{3}$, a correlation analysis revealed that the parameters obtained at the disc level were not independent of each other. For those parameters, therefore, we used seemingly unrelated regression (SUR) for parameter estimation. SUR accounts for correlated error terms among different equations by estimating the parameters of the equations simultaneously (Lei et al. 2005). Additionally, since parameters $b_{1}$ and $b_{3}$ did not follow a Gaussian distribution, models were fitted to their natural log-transformed values.

In samples where there was no observed decline in RD near to the bark, the second exponential term in Eq. 1 was omitted from the model. Logistic regression was therefore used to predict the occurrence of the $b_{4}$ parameter as a function of Age, $\mathrm{RW}_{\mathrm{b}}$, $\mathrm{RA}_{\mathrm{b}}, \mathrm{RW}_{\mathrm{h}}$ or GT. The predicted probabilities take values between 0 and 1 and were categorized into binary outcomes using a cut-point analysis (Hein and Weiskittel 2010). The sensitivity and specificity of all potential threshold values (from 0 to 1 , with an interval of 0.001) were calculated and the optimum was defined as the value giving the highest sum of sensitivity (true positives) and specificity (true negatives). Then, a linear mixedeffects model (Eq. 7) was fitted to the $b_{4}$ values for the instances where a decline was observed. The estimated parameters were then combined with results from the logistic model so that the second exponential term of Eq. 1 was only present when the predicted value was above the cut-point threshold.

The coefficients of the individual parameter models were then substituted back into Eq. 1 for the prediction of wood density. The performance of the full model was then evaluated using the error statistics given by Eqs. 2-6, and from fit indices calculated from the fixed effects of the model. Simulated wood density profiles were then constructed using predictions from the full model. The simulations were based on the mean values of the explanatory variables in the dominant, co-dominant and intermediate diameter classes. Predictions were then plotted to give a visual representation of the correlations between the explanatory variables and wood density profiles. To show the correlations of within-tree characteristics with wood density, different percentiles of the measured data were used for selected explanatory variables, whilst the remaining tree-level variables were fixed to their mean values within each dominance class. Disc-level variables were fixed to selected values (e.g. mean quartile values) within each disc level and dominance class combination.

A potential issue with the use of an exponential function in Eq. 1 to model the decline near the bark is that predictions cannot be extrapolated beyond the range of the data since they would approach zero very quickly. Therefore, we attempted to estimate a limit beyond which the predictions of the decline are no longer valid. For all discs in which the decline was observed, we calculated a relative rate of decline for which our reference was the average $\mathrm{RD}$ of rings $25-60\left(\mathrm{RD}_{60}\right)$. For each disc where the decline occurred, the difference between $\mathrm{RD}_{60}$ and the minimum $\mathrm{RD}\left(\mathrm{RD}_{\text {min }}\right)$ at the bark was calculated. The 95th percentile of the observed ratios of $\left(\mathrm{RD}_{60}-\mathrm{RD}_{\min }\right) / \mathrm{RD}_{60}$ was $27.2 \%$, which we used in the simulations as a limit of applicability of our model.

\section{Results}

When averaging the pith-to-bark profiles for all discs, $\mathrm{RD}$ was high near the pith and decreased rapidly in the first 12 growth rings, i.e. declined from $591.0 \mathrm{~kg} \mathrm{~m}^{-3}$ to a minimum of $473.8 \mathrm{~kg} \mathrm{~m}^{-3}$ between rings 10 and 15 . This was followed by a slow increase until a more constant value was reached between rings 25 and 60. Based on the criteria described above, the dataset was separated into two groups. It was observed that 106 of the 450 radial samples showed a gradual decline in $\mathrm{RD}$ near the bark and therefore required the inclusion of parameter $b_{4}$. In the remaining samples, there was no density decline towards the bark (Fig. 2). In the samples with a decline in ring density, annual ring width ranged from 0.1 to $3.8 \mathrm{~mm}$, with a mean value of $0.8 \mathrm{~mm}$, whilst RD ranged from 250.2 to $784.9 \mathrm{~kg} \mathrm{~m}^{-3}$ (mean= $504.4 \mathrm{~kg} \mathrm{~m}^{-3}$ ). In the samples with no decline, ring width ranged from 0.1 to $4.8 \mathrm{~mm}$ (mean=1.0 $\mathrm{mm}$ ) and $R D$ ranged from 262.5 to $839.5 \mathrm{~kg} \mathrm{~m}^{-3}$, with a mean value of $499.8 \mathrm{~kg} \mathrm{~m}^{-3}$.

A summary of the parameter values obtained in stage 1 of the model fitting process (Eq. 1) can be found in Table 4. For the individual parameter models in stage 2 , various combinations of just six explanatory variables were found to be significantly correlated with the variation of the parameters estimated using Eq. 7 (Tables 5 and 6). The occurrence of parameter $b_{4}$ was found to be significantly related to Age and $\mathrm{RW}_{\mathrm{h}}$, but was not related to $\mathrm{GT}, \mathrm{RW}_{\mathrm{b}}$ or $\mathrm{RA}_{\mathrm{b}}$. A predicted value threshold of 0.104 was used as the cut-point in the logistic model, above which a decline in RD near the bark was considered to be present (sensitivity $=0.63$, specificity $=$ 
Fig. 2 Ring density vs. cambial age for the 107 black spruce sample trees. Lines represent smoothing splines fitted to the data at each sampling height. a Discs (106) with a density decline close to the bark. b Discs (344) with no density decline close to the bark

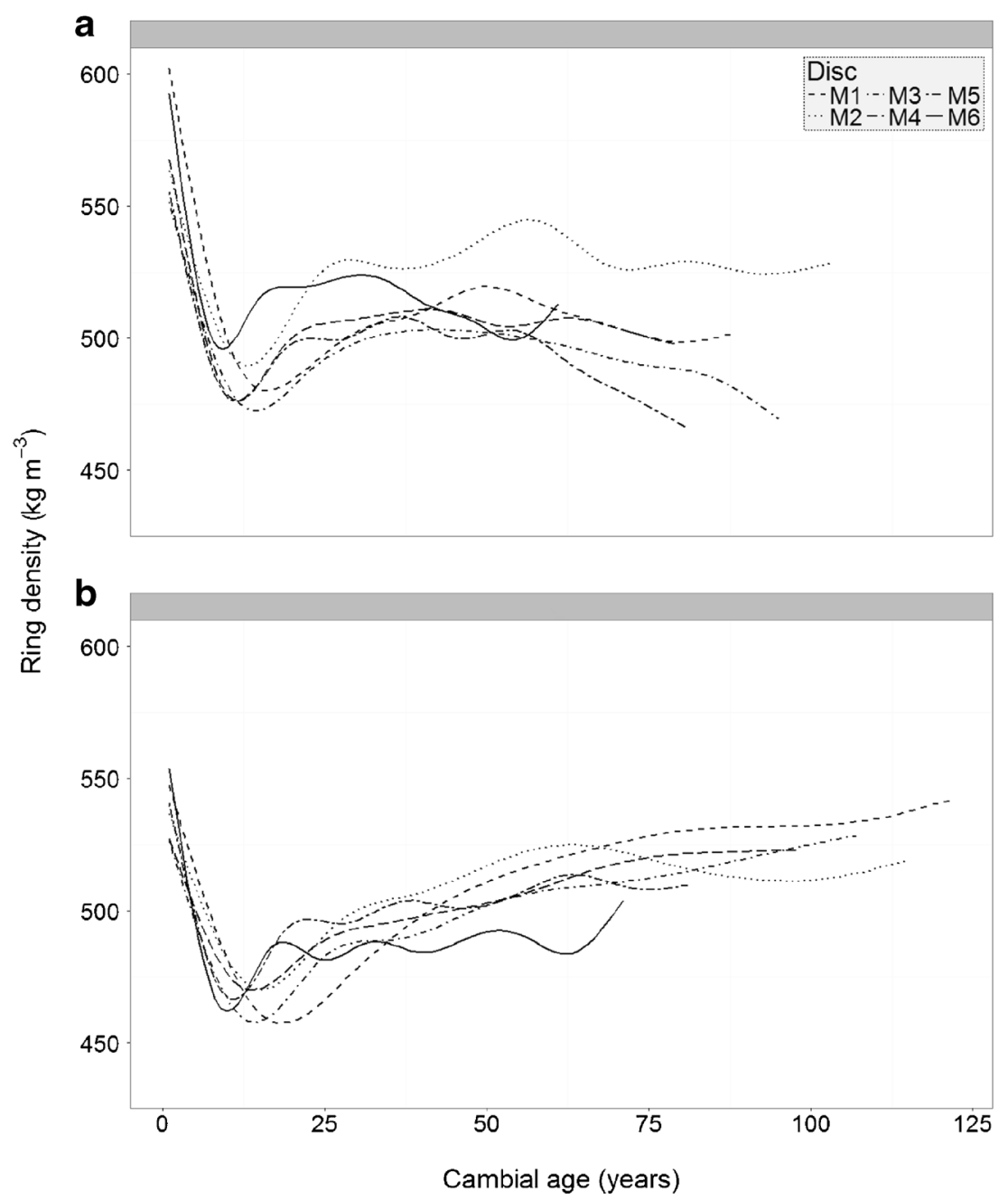

0.77). Then, in the model fitted to the observed occurrences of $b_{4}$, there were significant effects of Age and $h$, but no relationship with growth rate was detected (Table 6).

The disc-level models (stage 1) had moderate fit (mean $\left.R^{2}=0.37\right)$ and were generally unbiased, despite the large variability in the radial density profiles (Fig. 3a and Table 7). When predictions were calculated from the full model, the $R^{2}$ decreased to 0.17 , although the mean error and mean percentage error $\left(0.2 \mathrm{kgm}^{-3}\right)$ remained very low at $0.1 \mathrm{~kg} \mathrm{~m}^{-3}$ and $0.2 \%$, respectively (Fig. $3 \mathrm{~b}$ and Table 7 ).

Table 4 Descriptive statistics for parameters $b_{0}, b_{1}, b_{2}, b_{3}$ and $b_{4}$ obtained by fitting Eq. 1 to samples from individual discs

\begin{tabular}{llll}
\hline Parameter & Min. & Mean & Max. \\
\hline$b_{0}$ & 373.0 & 589.3 & 808.5 \\
$b_{1}$ & 0.010 & 0.259 & 2.188 \\
$b_{2}$ & 402.2 & 560.9 & 779.6 \\
$b_{3}$ & 0.005 & 5.764 & 77.960 \\
$b_{4}\left(b_{4}<0\right)$ & -0.098 & -0.050 & -0.020 \\
\hline
\end{tabular}

In general, lower minimum values of RD around the 15 th annual ring and higher maximum values near the bark were attained in the lower stem (Fig. 4). For a given cambial age, the $\mathrm{RD}$ of a slower-grown (i.e. lower value of $\mathrm{RW}_{1.3}$ ) intermediate tree was generally higher than for the other dominance classes, although the decline in wood density near the bark was more likely to occur (Fig. 5). However, even the RD profiles of dominant trees could also show a declining trend beyond a certain age (not shown).

The more detailed analysis of ring series close to the bark did not reveal any relationship between the occurrence of a decline and annual ring width. However, the proportion of latewood was, on average, lower in the discs with a density decline (Fig. 6).

\section{Discussion}

The wood density data in our study showed the typical radial pattern found in spruces that has also been observed in other studies (Alteyrac et al. 2005; Gardiner et al. 2011). Average 
Table 5 Coefficients and associated SEs for each explanatory variable for the $b_{0}, b_{1}, b_{2}$ and $b_{3}$ parameter models and adjusted $R^{2}$ values

\begin{tabular}{|c|c|c|c|c|c|c|}
\hline \multirow[t]{3}{*}{ Parameter } & \multirow[t]{3}{*}{ Intercept } & \multicolumn{5}{|l|}{ Variables } \\
\hline & & \multicolumn{2}{|l|}{ Tree level } & \multicolumn{2}{|l|}{ Disc level } & \multirow[t]{2}{*}{ Adjusted $R^{2}$} \\
\hline & & $H$ & $\mathrm{RW}_{1.3}$ & $h$ & $\mathrm{RW}_{\mathrm{p}}$ & \\
\hline$b_{0}$ & $\begin{array}{l}683.31^{* * *} \\
\pm 16.18\end{array}$ & $\begin{array}{l}-3.93 * * * \\
\pm 1.01\end{array}$ & & $\begin{array}{l}6.79 * * * \\
\pm 1.30\end{array}$ & $\begin{array}{l}-38.21 * * * \\
\pm 6.03\end{array}$ & 0.14 \\
\hline $\ln \left(b_{1}\right)$ & $\begin{array}{l}-0.96 * * * \\
\pm 0.15\end{array}$ & $\begin{array}{l}-0.05 * * * \\
\pm 0.01\end{array}$ & & $\begin{array}{l}0.06^{* * *} \\
\pm 0.01\end{array}$ & & 0.09 \\
\hline$b_{2}$ & $\begin{array}{l}643.70^{* * * *} \\
\pm 6.80\end{array}$ & & $\begin{array}{l}-70.54 * * * \\
\pm 6.17\end{array}$ & $\begin{array}{l}-5.00^{* * *} \\
\pm 0.92\end{array}$ & & 0.25 \\
\hline $\ln \left(b_{3}\right)$ & $\begin{array}{l}0.71 * * \\
\pm 0.24\end{array}$ & $\begin{array}{l}0.06^{* * *} \\
\pm 0.01\end{array}$ & & $\begin{array}{l}-0.11 * * * \\
\pm 0.02\end{array}$ & & 0.08 \\
\hline
\end{tabular}

$H$ total height of the tree, $R W_{1.3}$ mean ring width from cambial age 25 to 60 of the disc at breast height, $h$ disc position along the stem, $R W_{p}$ average ring width of the first three rings

$* 0.05 ; * * 0.01 ; * * * 0.001$

ring density was high near the pith and decreased rapidly outwards, followed by a slow increase until values stabilised between growth rings 25 and 60 . This pattern corresponds to the type II pith-to-bark profile described by Panshin and De Zeeuw (1980).

Investigating the complex interrelationships between cambial age, growth rate and height along the stem is recognised as one of the most difficult aspects of wood density studies (e.g. Alteyrac et al. 2005; Gardiner et al. 2011). The highly variable radial patterns among samples, particularly in the juvenile wood zone, proved difficult to incorporate into a single analysis. However, modelling individual profiles in a first stage and then constructing linear models for those parameters in a second proved to be a robust solution. The choice of an equation containing three separate components allowed enough flexibility to represent the large variation in density profiles. The first two terms in the equation are capable of describing the type II density pattern previously described, whilst the final exponential term was included when it was necessary to model a decline close to the bark.

The relatively poor fit of the full model in this study could be explained by the fact that, despite its classification as a type II species, wood density profiles in black spruce are, in reality, extremely variable. This variability will inevitably increase the absolute magnitude of the model errors by increasing the deviation between the observed and predicted ring density. However, the sampling strategy in this study was designed to capture the natural variability found in black spruce unmanaged stands by sampling across a range of tree ages and sizes. By modelling the parameters of the individual density profiles, we were able to reduce these errors when compared with initial model fits to the pooled dataset. The low fit indices for the $b_{1}$ and $b_{3}$ parameters were most likely a result of the large variability in the initial decline near the pith.

Table 6 Coefficients and associated SEs for each explanatory variable for the $b_{4}$ parameter model and adjusted $R^{2}$ values calculated from the fixed effects

\begin{tabular}{lllll}
\hline Parameter & Intercept & Variables & \\
\cline { 3 - 4 } & & Tree level & Disc level & Adjusted $R^{2}$ \\
\cline { 3 - 4 } & & Age & $h$ & $\mathrm{RW}_{\mathrm{h}}$ \\
\hline$b_{4}{ }^{\mathrm{a}}$ & $-5.14^{* * *}$ & $0.05^{* * *}$ & $-2.15^{* *}$ \\
& \pm 1.32 & \pm 0.01 & \pm 0.73 \\
$b_{4}<0$ & $-8.62 \mathrm{e}-2^{* * *}$ & $4.48 \mathrm{e}-4^{* * *}$ & $-2.97 \mathrm{e}^{-3 * * *}$ & \pm 0.00 \\
& \pm 0.01 & \pm 0.00 & \pm 0.00 & \\
\hline
\end{tabular}

$* 0.05 ; * * 0.01 ; * * * 0.001$

Age tree age at breast height, $h$ disc position along the stem, $R W_{h}$ mean ring width from cambial age 25 to 60 of each disc

${ }^{\text {a }}$ Binary logistic model for testing the occurrence of the decline 
Fig. 3 a Model residuals of the stage 1 predictions vs. cambial age. b Residuals of the stage 2 predictions against cambial age. Percentiles of the residuals are represented by the different shades of grey. The grey dashed line represents the median value of the residuals for a given cambial age

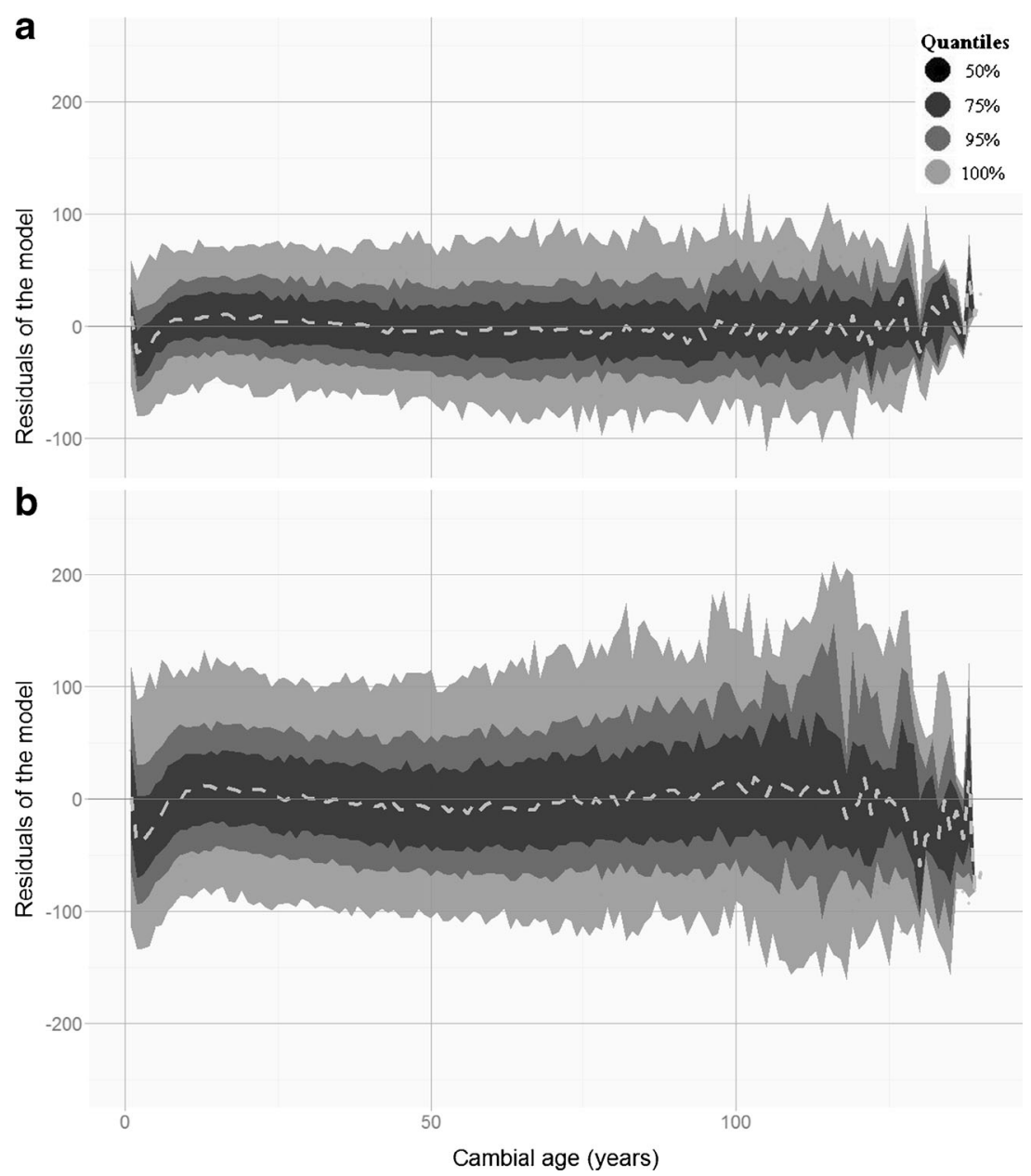

The high density of wood adjacent to the pith in black spruce has been attributed to high earlywood density and low earlywood proportion (Alteyrac et al. 2005; Koubaa et al. 2005). Both earlywood density and latewood proportion tend to decline rapidly in the first few rings, leading to a decline in overall ring density. The wood adjacent to the pith,

Table 7 Fit indices and error statistics calculated from the fixed effects of the disc-level models and full model given by Eq. 1

\begin{tabular}{|c|c|c|c|c|c|c|}
\hline & $R^{2}$ & $\mathrm{ME}$ & $|\mathrm{ME}|$ & RMSE & $\mathrm{ME} \%$ & $|\mathrm{ME}| \%$ \\
\hline \multicolumn{7}{|c|}{ Disc-level models } \\
\hline Min. & 0.00 & -26.1 & 13.8 & 17.6 & -6.4 & 2.8 \\
\hline 1st Qu. & 0.20 & -0.3 & 23.2 & 29.4 & 0.0 & 4.7 \\
\hline Median & 0.38 & 0.9 & 26.4 & 33.8 & 0.2 & 5.4 \\
\hline Mean & 0.37 & 0.9 & 27.7 & 35.6 & 0.3 & 5.5 \\
\hline 3rd Qu. & 0.54 & 2.1 & 31.6 & 40.3 & 0.4 & 6.2 \\
\hline Max. & 0.86 & 23.2 & 54.4 & 75.0 & 4.8 & 10.3 \\
\hline \multicolumn{7}{|l|}{ Full model } \\
\hline Mean & 0.17 & 0.1 & 44.9 & 58.1 & 0.2 & 9.0 \\
\hline
\end{tabular}

termed 'flexure wood' by Telewski (1989), is thought to be formed in response to complex loading patterns to which trees are subjected at a young age. This high density wood also has steeply oriented microfibrils that confer low stiffness, and together, these characteristics ensure that trees are flexible enough to withstand high stresses without breaking. Differences in local conditions between individual trees may lead to different initial values of density and, therefore, different rates of decline.

As expected, ring density was negatively correlated to the average ring width of the mature wood. In our analysis, the best predictions were obtained between rings 25 and 60 . However, these must not be taken as precise limits. Rather, they are indicative of an overall negative relationship between radial growth rate and wood density in the part of the profile described by the second term of our equation. Accordingly, dominant trees tended to have lower density rings in the period preceding the decline than the trees in other dominance classes. This is in accordance with observations in Sitka spruce that, for a large range of ring widths, latewood width remains relatively constant between rings, so that variation in ring width is closely related to earlywood width (Brazier 
Fig. 4 Simulated radial density profiles with cambial age at different sampling heights $(h)$ for a typical dominant tree. Tree-level variables (i.e. $H$, Age and $\mathrm{RW}_{1.3}$ ) were set to their mean values for dominant trees, whilst disc-level variables (i.e. $h, \mathrm{RW}_{\mathrm{p}}, \mathrm{RW}_{\mathrm{h}}$ ) were set at their mean values for each disc height in a dominant tree. Lines represent the mean predictions at successive disc heights $(M 1-M 6)$ from the stem base

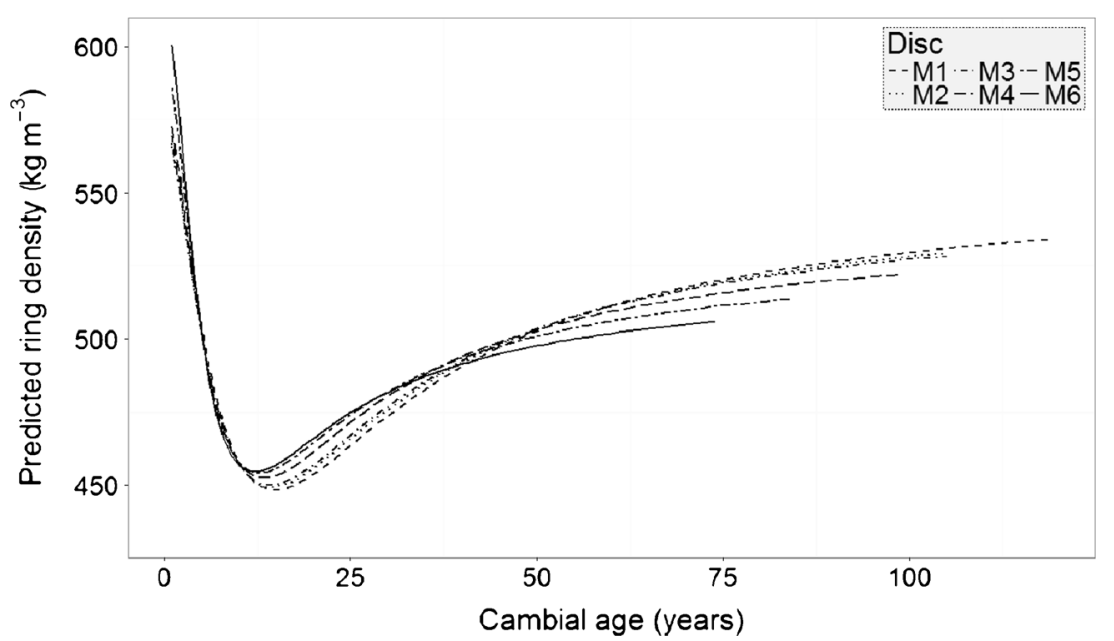

1970). Similar results have been found in black spruce (Zhang et al. 1996) and jack pine (Pinus banksiana Lamb.) (Savva et al. 2010).

A gradual decrease in ring density after approximately 60 years was observed in around $24 \%$ of the samples, which, to our knowledge, has been reported in very few studies (e.g. Schär and Schweingruber 1987). The latter study reported a similar density decline in subalpine fir (Abies lasiocarpa (Hook.) Nutt.). This was associated with a reduction in latewood density after approximately 50 years, whilst earlywood density remained relatively constant. Elsewhere, evidence of a positive correlation between growth rate and wood properties has been reported, but such correlations appear to be mainly related to water availability. For example, in young loblolly pine (Pinus taeda L.), higher ring density associated with faster radial growth was related to the increased growth of latewood in wetter growing seasons (Cregg et al. 1988). Conversely, a simultaneous decrease in ring width and wood density in Norway spruce coincided with increased early season rainfall, which resulted in the increased production of earlywood (Wimmer and Downes 2003).

In the current study, the observed decline in wood density typically spanned several years, with a faster rate of decline at higher cambial ages. For these reasons, it is highly unlikely that it was related to water availability. The decline in wood density near the bark was associated with higher cambial ages and slower growth rates in the mature wood, i.e. in the period before the onset of the decline. Comparable studies of black spruce wood density have tended to sample either young or dominant trees (e.g. Zhang et al. 1996; Alteyrac et al. 2005).
Fig. 5 Simulated radial density profiles with cambial age at breast height $(h=1.3 \mathrm{~m})$ for trees in each dominance class. The horizontal line denotes the proposed limit of application of our model. Treelevel variables (i.e. $H$, Age and $\mathrm{RW}_{1.3}$ ) were set to their mean values within each dominance class, whilst disc-level variables (i.e. $\mathrm{RW}_{\mathrm{p}}, \mathrm{RW}_{\mathrm{h}}$ ) were set at their mean values at breast height within each dominance class

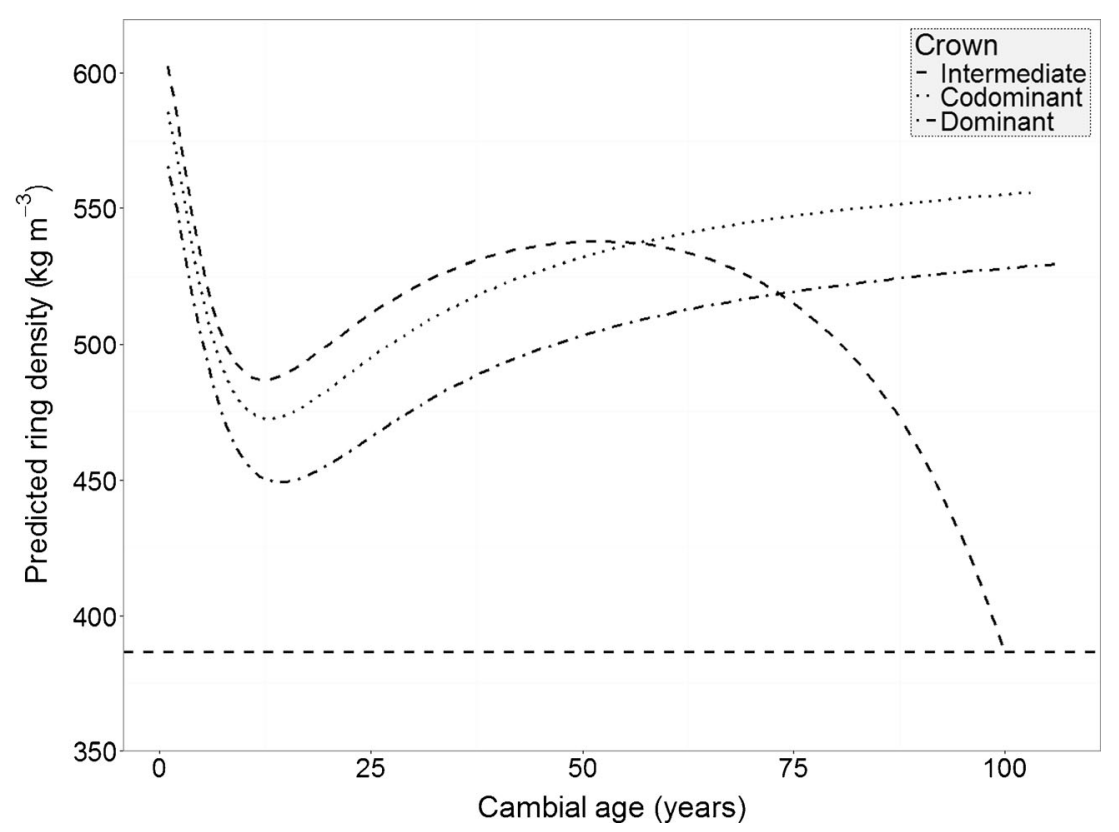


Fig. 6 Graph of average latewood proportion against the year of annual ring formation for the two groups of ring series that were analysed under a microscope

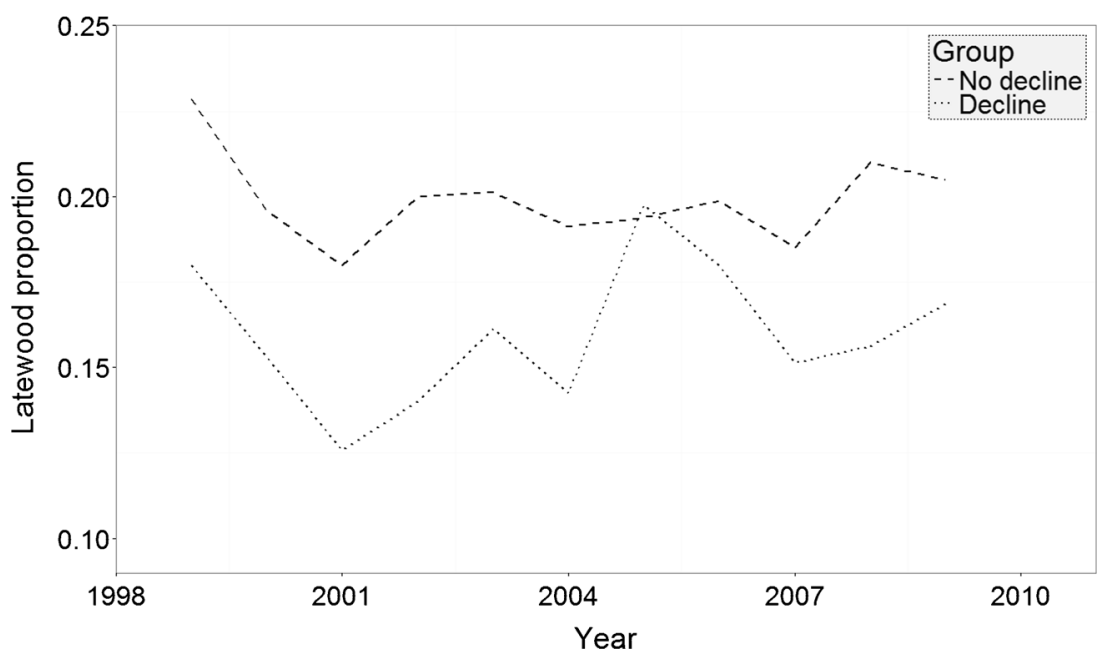

Measures of mean growth rate and the slope of mean growth rate ('growth level' and 'growth trend', respectively) have been used to predict tree mortality in Norway spruce (Bigler and Bugmann 2003, 2004), although in our study, growth trend was not significantly correlated with the decline in wood density. Trees with little or no latewood-a phenomenon referred to as 'starvation wood' by Brazier (1977) — have also been reported growing in poor stands in Scandinavia. Examination of the microscopy samples in our study tended to confirm the existence of a similar type of wood in samples with a density decline, which contained a low proportion of latewood. It is possible that, in situations where resources are severely limited, black spruce trees can only maintain radial growth by producing lower density wood (Swenson and Enquist 2007). The observed decline in wood density may therefore imply a reduction in aboveground resource allocation. Such a change in resource allocation may help increase the longevity of old, declining trees (Robichaud and Methven 1993).

Although height along the stem had a significant influence on all the parameters of Eq. 7, its overall effect varied with cambial age. Other studies on Norway spruce have found a weak or insignificant pattern of variation in wood density with position in the stem (Mäkinen et al. 2007; Jyske et al. 2008). In the current study, wood density tended to increase with height in the stem up to a cambial age of approximately 45 years, which is in agreement with the findings of Alteyrac et al. (2005). It has been suggested that this is due to the physiological ageing of the cambium, so that juvenile wood formed higher up the stem has more mature traits than wood produced at young cambial ages lower down the stem (Larson 1969; Alteyrac et al. 2005). However, the fact that the trend was reversed beyond ring 45 suggests that more work is necessary to fully understand the factors driving the variations in wood density with height along the stem.

\section{Conclusions}

This study investigated wood density variations in black spruce stems growing in unmanaged stands. A two-stage modelling approach was justified since it helped separate the interrelated effects of cambial age, growth rate and height along the stem on wood density. In mature wood, radial growth rate was found to be negatively correlated with wood density. However, declining trends in annual ring density near the bark were observed, which were found to be more common in old and slow-growing trees. We hypothesise that such trends reflect a gradual reduction in tree vigour over the life of the tree.

The observed decline in wood density has implications for forest management because silvicultural interventions designed to reduce the effects of the decline by promoting vigorous growth, such as commercial thinning, may need to be considered. An appropriate rotation age may also be used as a means of avoiding the decline in wood density. In addition to any considerations about its possible effect on end-product properties, the occurrence of the decline could also have implications for aboveground biomass estimations, which could be improved by including the conditions for when a decline might occur. Future work should be conducted to investigate the possible impacts of this phenomenon on carbon allocation to other parts of the tree.

Acknowledgments This study is part of a project supported by the NSERC ForValueNet Strategic Network. The authors would like thank Daniel Corbett and Northwest Regional Growth and Yield field staff at Northwest Science and Information (OMNR) for the field work and field data. Many thanks also to our colleagues who helped with the laboratory work, including Stephane Comeault, Dr. Xiaodong Wang, Stephen Elliott, Brent Forbes, Dr. Marek Holpit and Dr. Thakur Upadhyay. We also sincerely thank Dr. Jean-Michel Leban and two anonymous reviewers for their useful comments on the manuscript. 
Funding Financial support for this project came from NSERCForValueNet and Living Legacy Trust.

\section{References}

Achim A, Gardiner BA, Leban J-M, Daquitane R (2006) Predicting the branching properties of Sitka spruce grown in Great Britain. NZ J For Sci 36:246-264

Alteyrac J, Zhang SY, Cloutier A, Ruel JC (2005) Influence of stand density on ring width and wood density at different sampling heights in black spruce (Picea mariana (Mill.) BSP). Wood Fiber Sci 37: 83-94

Auty D, Achim A (2008) The relationship between standing tree acoustic assessment and timber quality in Scots pine and the practical implications for assessing timber quality from naturally regenerated stands. Forestry 81:475-487

Auty D, Gardiner BA, Achim A, Moore JR, Cameron AD (2012) Models for predicting microfibril angle variation in Scots pine. Ann For Sci 70:209-218

Bigler C, Bugmann H (2003) Growth-dependent tree mortality models based on tree rings. Can J Forest Res 33:210-221

Bigler C, Bugmann H (2004) Predicting the time of tree death using dendrochronological data. Ecol Appl 14:902-914

Bouriaud O, Bréda N, Moguédec G, Nepveu G (2004) Modelling variability of wood density in beech as affected by ring age, radial growth and climate. Trees-Struct Funct 18:264-276

Boyle TJB, Balatinecz JJ, McCaw PM (1989) Genetic control of some wood properties in black spruce. Proceedings of the Twenty-First Meeting of the Canadian Tree Improvement Association, Part 2, pp $17-21$

Brazier JD (1970) Timber improvement. II: The effect of vigour on young growth Sitka spruce. Forestry 43:135-150

Brazier JD (1977) The effect of forest practices on quality of the harvested crop. Forestry 50:49-66

Core Team R (2013) R: a language and environment for statistical computing. R Foundation for Statistical Computing, Vienna

Cregg BM, Dougherty PM, Hennessey TC (1988) Growth and wood quality of young loblolly pine trees in relation to stand density and climatic factors. Can J Forest Res 18:851-858

De Vries WIM, Reinds GJ, Gundersen PER, Sterba H (2006) The impact of nitrogen deposition on carbon sequestration in European forests and forest soils. Glob Change Biol 12:1151-1173

Duchateau E, Longuetaud F, Mothe F, Ung C, Auty D, Achim A (2013) Modelling knot morphology as a function of external tree and branch attributes. Can J For Res 43:266-277

Evans R (1994) Rapid measurement of the transverse dimensions of tracheids in radial wood sections from Pinus radiata. Holzforschung 48:68-172

Franceschini T, Bontemps JD, Gelhaye P, Rittie D, Herve JC, Gegout JC, Leban JM (2010) Decreasing trend and fluctuations in the mean ring density of Norway spruce through the twentieth century. Ann For Sci 67:816-826

Franceschini T, Lundquist SO, Bontemps JD, Grahn T, Olson L, Evans R, Leban JM (2012) Empirical models for radial and tangential fibre width in tree ring of Norway spruce in north-western Europe. Holsforschung 66:219-230

Franceschini T, Longuetaud F, Bontemps JD, Bouriaud O, Caritey BD, Leban JM (2013) Effect of ring width, cambial age, and climatic variables on the within-ring wood density profile of Norway spruce Picea abies (L.) Karst. Trees 27:913-925

Gardiner B, Leban JM, Auty D, Simpson H (2011) Models for predicting wood density of British-grown Sitka spruce. Forestry 84:119-132
Guilley E, Hervé JC, Nepveu G (2004) The influence of site quality, silviculture and region on wood density mixed model in Quercus petraea Liebl. Forest Ecol Manag 189:111-121

Hall JP (1984) The relationship between wood density and growth rate and the implications for the selection of black spruce plus trees. For Res Cent Inf Rep N-X-224, Can For Serv, St-John's Newfoundland

Hein S, Weiskittel AR (2010) Cutpoint analysis for models with binary outcomes: a case study on branch mortality. Eur J Forest Res 129: 585-590

Jaakkola T, Mäkinen H, Saranpää P (2005) Wood density in Norway spruce: changes with thinning intensity and tree age. Can J Forest Res 35:1767-1778

Jozsa LA, Middleton GR (1994) A discussion of wood quality attributes and their practical implications. Forintek Canada Corp,Vancouver, BC Special Publ. No. SP-34

Jyske T, Mäkinen H, Saranpää P (2008) Wood density within Norway spruce stems. Silva Fenn 42:439-455

Ketterings QM, Coe R, van Noordwijk M, Ambagau Y, Palm CA (2001) Reducing uncertainty in the use of allometric biomass equations for predicting above-ground tree biomass in mixed secondary forests. Forest Ecol Manag 146:199-209

Koga S, Zhang SY (2004) Inter-tree and intra-tree variations in ring width and wood density components in balsam fir (Abies balsamea). Wood Sci and Technol 38:149-162

Koubaa A, Zhang SY, Isabel N, Beaulieu J, Bousquet J (2000) Phenotypic correlations between juvenile-mature wood density and growth in black spruce. Wood Fiber Sci 32:61-71

Koubaa A, Isabel N, Zhang SY, Beaulieu J, Bousquet J (2005) Transition from juvenile to mature wood in black spruce (Picea Mariana (Mill.) BSP). Wood Fiber Sci 37:445-455

Larson PR (1969) Wood formation and the concept of wood quality. Yale Univ Sch For Bull 74:1-54

Lei YC, Zhang SY, Jiang Z (2005) Models for predicting lumber bending MOR and MOE based on tree and stand characteristics in black spruce. Wood Sci Technol 39:37-47

Lohrasebi H, Mabee WE, Roy DN (1999) Chemistry and pulping feasibility of compression wood in black spruce. J Wood Chem Technol 19:13-25

Mäkinen H, Saranpää P, Linder S (2002) Wood-density variation of Norway spruce in relation to nutrient optimization and fibre dimensions. Can J Forest Res 32:185-194

Mäkinen H, Jaakkola T, Piispanen R, Saranpää P (2007) Predicting wood and tracheid properties of Norway spruce. Forest Ecol Manag 241: $175-188$

Marconetto MB (2010) Paleoenvironment and anthracology: determination of variations in humidity based on anatomical characters in archealogical plant charcoal (Ambato Valley, Catamarca, Argentina). J Archaeol Sci 37:1186-1191

McLane SC, LeMay VM, Aitken SN (2011) Modeling lodgepole pine radial growth relative to climate and genetics using universal growth-trend response functions. Ecol Appl 21:776-788

Panshin A, De Zeeuw C (1980) Textbook of wood technology. McGrawHill, New York

Parresol BR (1999) Assessing tree and stand biomass: a review with examples and critical comparisons. Forest Sci 45:573-593

Pinheiro JC, Bates DM (2000) Mixed-effects models in S and S-PLUS. Springer, New York

Plonski WL (1956) Normal yield tables for black spruce, jack pine, aspen and white birch in northern Ontario. Ont Dept Lands For Toronto, ON Rep 24:229-244

Risi J, Zeller E (1960) Specific gravity of the wood of Black Spruce (Picea Mariana (Mill.) BSP) grown on a Hylocomium-Cornus site type. Univ Laval, For Res Found. Québec, Canada

Robichaud E, Methven IR (1993) The effect of site quality on the timing of stand breakup, tree longevity, and the maximum attainable height of black spruce. Can J For Res 23:1514-1519 
Savva Y, Koubaa A, Tremblay F, Bergeron Y (2010) Effects of radial growth, tree age, climate, and seed origin on wood density of diverse jack pine populations. Trees-Struct Funct 24:53-65

Schär E, Schweingruber FH (1987) Nacheiszeitliche Stammfunde aus Grächen im Wallis. Schweizerische Zeitschrift für das Forstwesen 138:497-515

Simpson HL, Denne MP (1997) Variation of ring width and specific gravity within trees from unthinned Sitka spruce spacing trial in Clocaenog, North Wales. Forestry 70:31-45

Smith DM, Larson BC, Kelty MJ, Ashton PM (1997) The practice of silviculture: applied forest ecology. Wiley, New York

Swenson NG, Enquist BJ (2007) Ecological and evolutionary determinants of a key plant functional trait: wood density and its community-wide variation across latitude and elevation. Am J Botany 94:451-459

Telewski FW (1989) Structure and function of flexure wood in Abies fraseri. Tree Physiol 5:113-121

van Buijtenen JP (1982) Fiber for the future. Tappi 65:10-12

Wang L, Payette S, Begin Y (2002) Relationships between anatomical and densitometric characteristics of black spruce and summer temperature at tree line in northern Quebec. Can J Forest Res 32:477-486
Wimmer R, Downes GM (2003) Temporal variation of the ring widthwood density relationship in Norway spruce grown under two levels of anthropogenic disturbance. IAWA J 24:53-61

Zhang SY (1998) Effect of age on the variation, correlations and inheritance of selected wood characteristics in black spruce (Picea mariana). Wood Sci Technol 32:197-204

Zhang SY, Morgenstern EK (1995) Genetic-variation and inheritance of wood density in black spruce (Picea mariana) and its relationship with growth - implications for tree breeding. Wood Sci Technol 30: 63-75

Zhang SY, Owoundi RE, Nepveu G, Mothe F, Dhote JF (1993) Modeling wood density in European oak (Quercus petraea and Quercus robur) and simulating the silvicultural influence. Can J Forest Res 23:2587-2593

Zhang SY, Simpson D, Morgenstern EK (1996) Variation in the relationship of wood density with growth in 40 black spruce (Picea mariana) families grown in New Brunswick. Wood Fiber Sci 28: 91-99

Zhang SY, Chauret G, Ren HQ, Desjardins R (2002) Impact of initial spacing on plantation black spruce lumber grade yield, bending properties, and MSR yield. Wood Fiber Sci 34:460-475 